\title{
Atmospheric circulation types and extreme areal precipitation in southern central Europe
}

\author{
Jucundus Jacobeit, Markus Homann, Andreas Philipp, and Christoph Beck \\ Institute of Geography, University of Augsburg, Augsburg, Germany \\ Correspondence to: Jucundus Jacobeit (jacobeit@geo.uni-augsburg.de)
}

Received: 15 January 2017 - Accepted: 15 March 2017 - Published: 5 April 2017

\begin{abstract}
Gridded daily rainfall data for southern central Europe are aggregated to regions of similar precipitation variability by means of S-mode principal component analyses separately for the meteorological seasons. Atmospheric circulation types (CTs) are derived by a particular clustering technique including large-scale fields of SLP, vertical wind and relative humidity at the $700 \mathrm{hPa}$ level as well as the regional rainfall time series. Multiple regression models with monthly $\mathrm{CT}$ frequencies as predictors are derived for monthly frequencies and amounts of regional precipitation extremes (beyond the $95 \%$ percentile). Using predictor output from different global climate models (ECHAM6, ECHAM5, EC-EARTH) for different scenarios (RCP4.5, RCP8.5, A1B) and two projection periods (2021-2050, 2071-2100) leads to assessments of future changes in regional precipitation extremes. Most distinctive changes are indicated for the summer season with mainly increasing extremes for the earlier period and widespread decreasing extremes towards the end of the 21 st century, mostly for the strong scenario. Considerable uncertainties arise from the predictor use of different global climate models, especially during the winter and spring seasons.
\end{abstract}

\section{Introduction}

Within the Austrian-German research project WETRAX (Weather patterns, cyclone tracks, and related precipitation extremes, see Hofstätter et al., 2015), extreme areal precipitation in southern central Europe has been studied in the context of climate change. A common approach for studying changes in precipitation extremes is to use links to the large-scale atmospheric circulation whose changes can be investigated quite reliably thus also allowing to assess changes in precipitation extremes from identified circulation changes. This paper refers to particular circulation types (CTs) being important for such extreme events and their projected changes resulting from future frequency changes of these CTs.

\section{Data}

For parts of southern Central Europe, a gridded daily precipitation set with $6 \mathrm{~km}$ horizontal resolution has been generated for the period 1951-2006 by the Austrian Zentralanstalt für Meteorologie und Geodynamik (ZAMG) including data from the German and Czech weather services (Hofstätter et al., 2015). Atmospheric variables (like SLP, geopotential heights, vertical wind, specific and relative humidity) for defining circulation types have been extracted from the NCEP1 re-analysis data set. Climate model data for future projection periods (2021-2050, 2071-2100) have been taken from ECHAM6 and EC-EARTH models for the RCP4.5 and RCP8.5 scenarios and from the older ECHAM5 model for the A1B scenario. The ECHAM model data included several realizations (3 for ECHAM6 and 2 for ECHAM5), only for EC-EARTH just one realization was available.

\section{Methods}

To determine regions with similar precipitation variability, S-mode principal component analyses have been applied to the gridded rainfall data for the meteorological seasons DJF, MAM, JJA and SON. Figure 1 displays the resulting regions for spring and summer. Based on weighted means of daily precipitation for these regions (weighted by the corresponding loading of each grid box), extreme precipitation events 

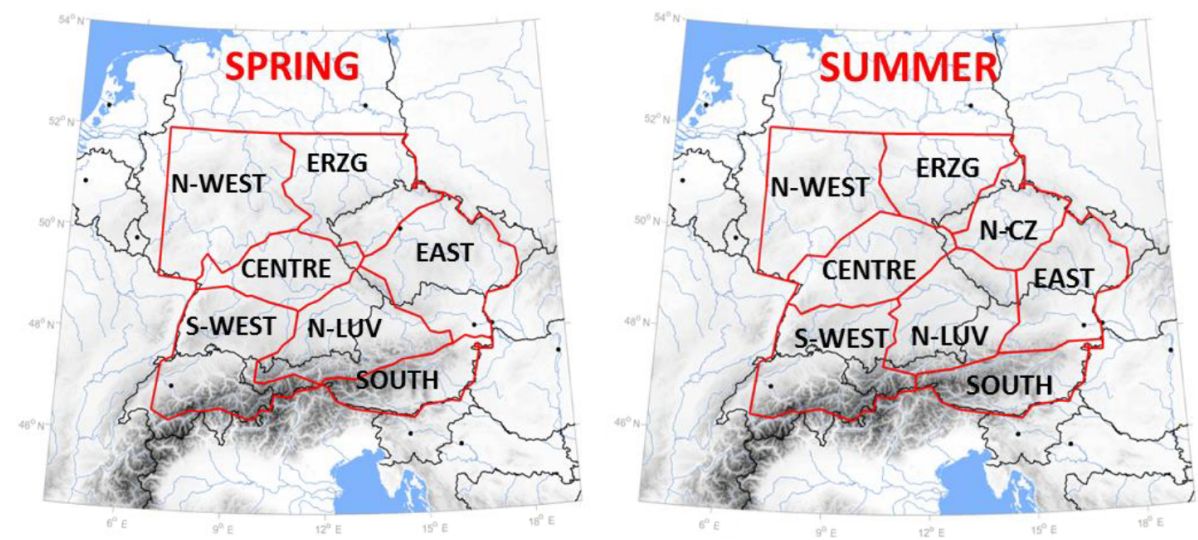

Figure 1. Regions of similar precipitation variability derived by S-mode PCAs in spring and summer 1951-2006.

have been defined by means of the $95 \%$ percentile in each season (higher percentiles would imply an insufficient number of events for statistical assessments).

Large-scale atmospheric circulation types have been derived by using the COST733 classification software (Philipp et al., 2016) and gridded daily NCEP1 reanalysis data. To evaluate the performance of particular circulation type classifications with respect to regional precipitation extremes, multiple regression models have been derived for monthly frequencies of extreme regional precipitation and monthly extreme precipitation amounts with monthly frequencies of circulation types as multiple predictors. In each case, 5 regression models have been derived with 5 different calibration and validation periods (by defining different decades of the observation period for validation) in order to account for non-stationarities in the statistical relationships. As best performing CT classification (in terms of explained variance for monthly frequencies and monthly amounts of extreme regional precipitation), the SANDRA clustering method (simulated annealing and diversified randomization, see Philipp et al., 2007) has finally been applied with the following specifications:

- SLP, vertical wind and relative humidity ( $700 \mathrm{hPa}$ level) as large-scale variables with different weights for cluster classification;

- further inclusion of regional rainfall time series (i.e. applying the conditioned mode of classification);

- uniform number of 18 clusters (medium size according to COST733 standards).

Figure 2 gives two examples for resulting circulation types, represented by the centroid patterns of the included variables.

Finally, future assessments of changes in extreme regional precipitation are based on modified occurrence frequencies of these circulation types in global climate model projections.

\section{Results}

Among the 18 circulation types per season, only some few ( 2 to 4 per rainfall region) are linked to regional precipitation extremes. In general, they include cut-off-low patterns mainly for southern and eastern regions of the study area, zonal types for northern and western regions, meridional patterns especially for the southern part, and mixed types (mainly with northwesterly flow) for the northern alpine area. The selected types in Fig. 2 include a spring trough pattern with extreme precipitation south of the main crest of the Alps and a summer cut-off low with highest precipitation rates along the northern rim of the Alps.

Concerning those circulation-types linked to extreme precipitation, there are only some few significant frequency changes during the observation period. For the future projection periods, we generally get an increase of zonal patterns in winter and similar or decreasing frequencies of CTs linked to extreme precipitation in summer. However, there are also some deviations for particular CTs between the different global climate models used in this study.

Figure 3 shows the frequency changes of extreme regional precipitation for the selected seasons spring and summer based on ECHAM6 predictors within the multiple regression models assessing frequency and amount (not shown) of extreme regional precipitation from monthly CT occurrence frequencies. In spring, significant $(95 \%$ level) increases around $10 \%$ are only present in the northern regions of the study area (north-western part and Erzgebirge region), confined to the strong scenario (RCP8.5) in the later period 2071-2100. In summer, a distinct contrast between the projection periods becomes apparent: the earlier one (20212050) mainly shows increases for the strong scenario (significant in 5 of the 8 regions), whereas the later period (20712100) generally displays significant decreases for the strong scenario. This contrast might be due to the superposition of increasing water vapour concentration in a warming atmosphere and increasing anticyclonic influence during summer 


\section{Circulation type 11, spring 1951-2006}
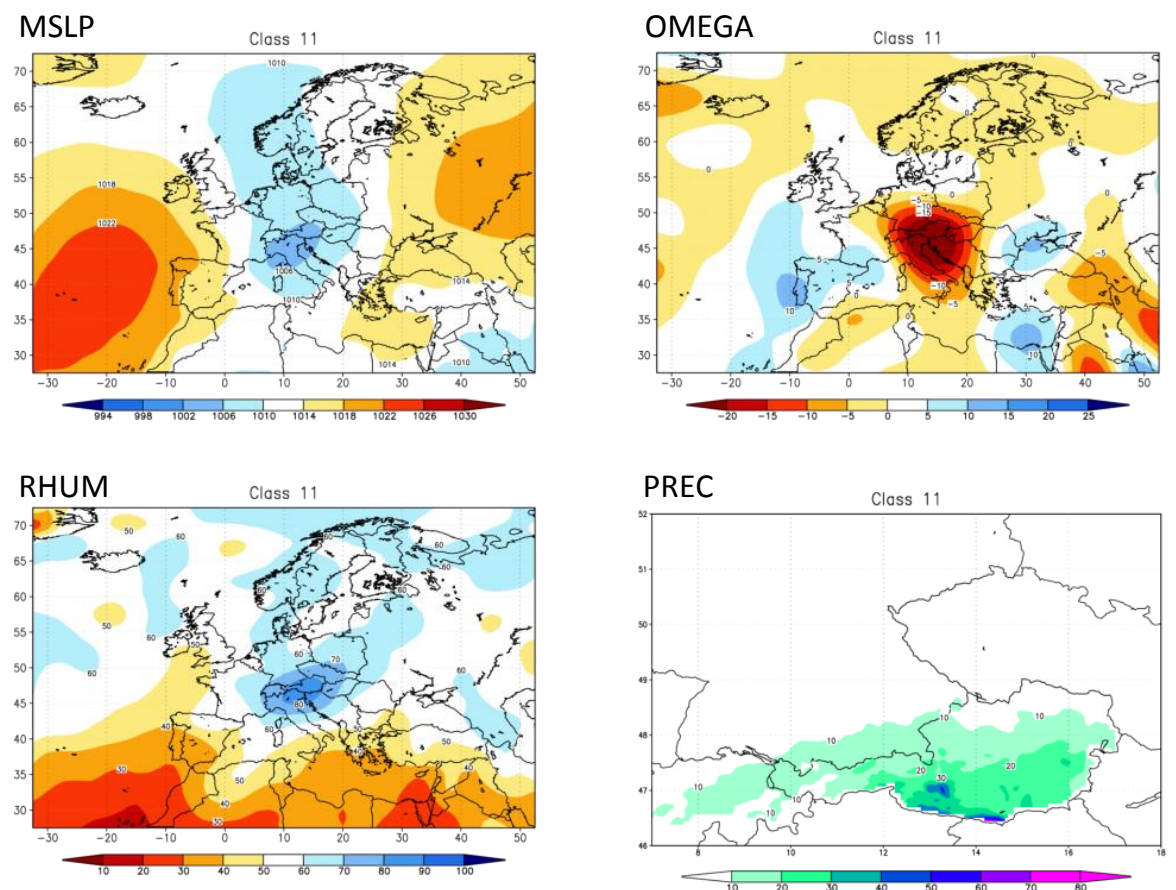

Circulation Type 5, summer 1951-2006
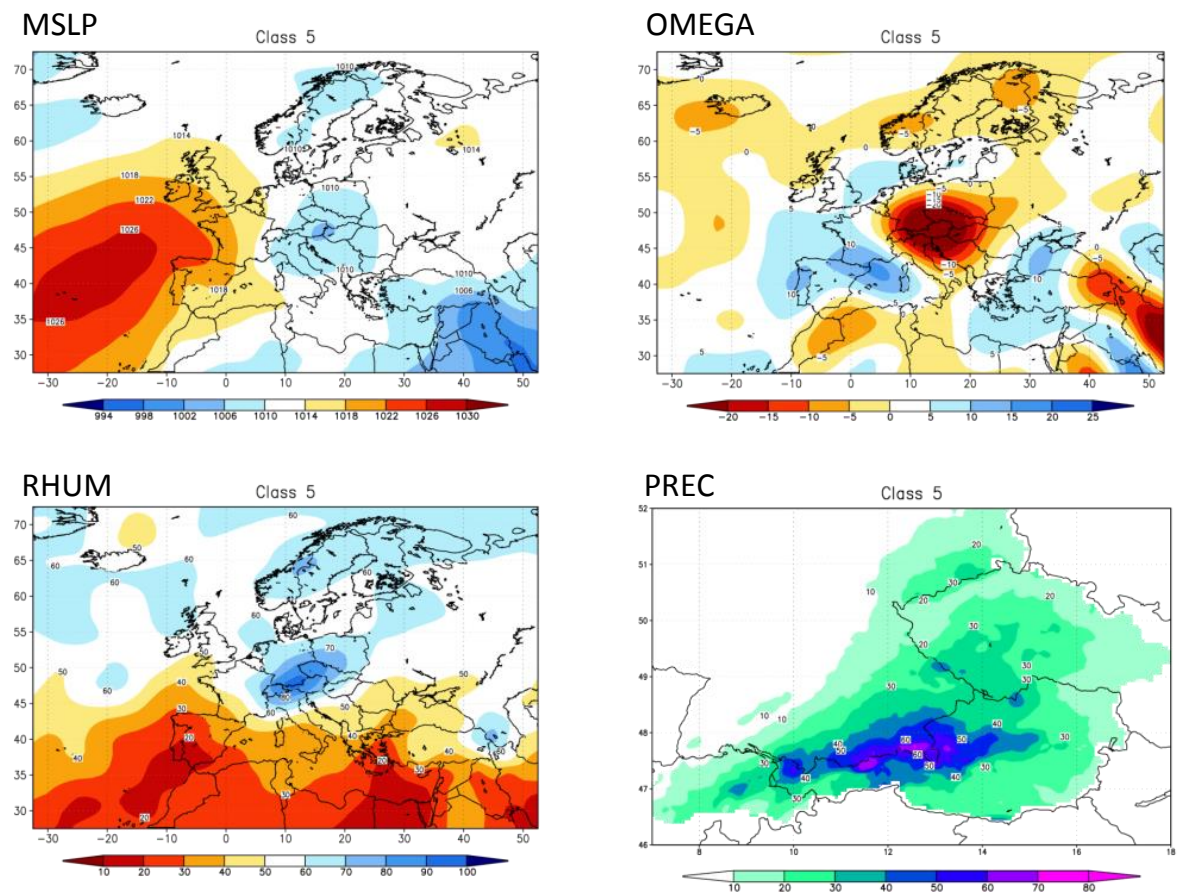

Figure 2. Centroid patterns for two selected Circulation Types (spring and summer) resulting from SANDRA cluster analyses including the variables mean sea level pressure (MSLP, hPa), vertical wind (OMEGA, $\mathrm{hPa} \mathrm{h}^{-1}$ ) and relative humidity $(\mathrm{RHUM}, \%)$ at the $700 \mathrm{hPa}$ level as well as daily precipitation rate (PREC, $\mathrm{mm} \mathrm{day}^{-1}$ ). 

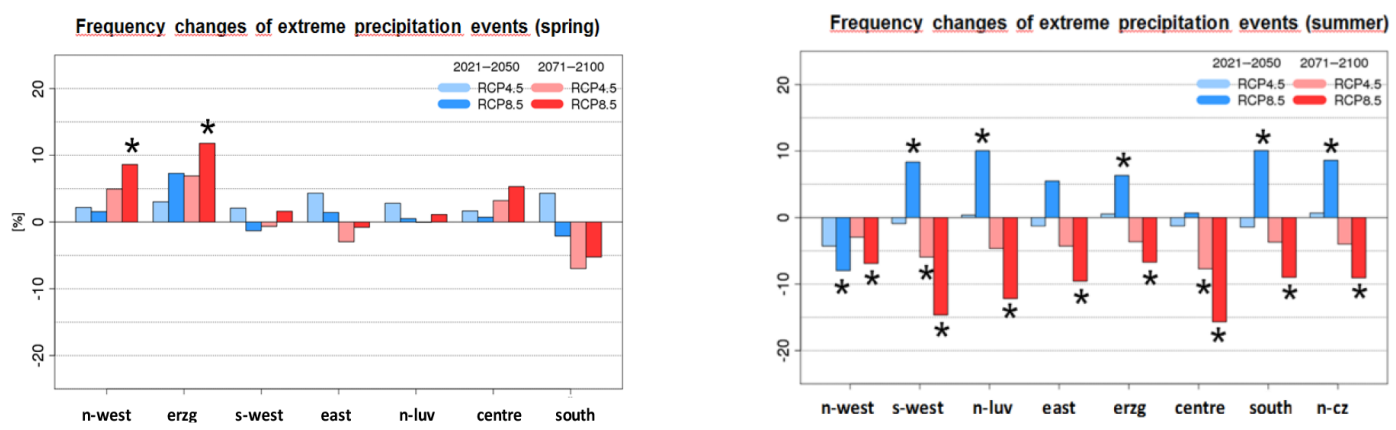

Figure 3. Frequency changes (\%) of extreme regional precipitation ( $>95 \%$ percentile) in spring and summer based on ECHAM6 predictors: Ensemble mean changes for two projection periods (2021-2050, 2071-2100) and two scenarios (RCP4.5 and RCP8.5) compared to the period 1971-2000. Significant changes (95\% level) are indicated by *.

\section{Frequency changes of extreme precipitation in summer}

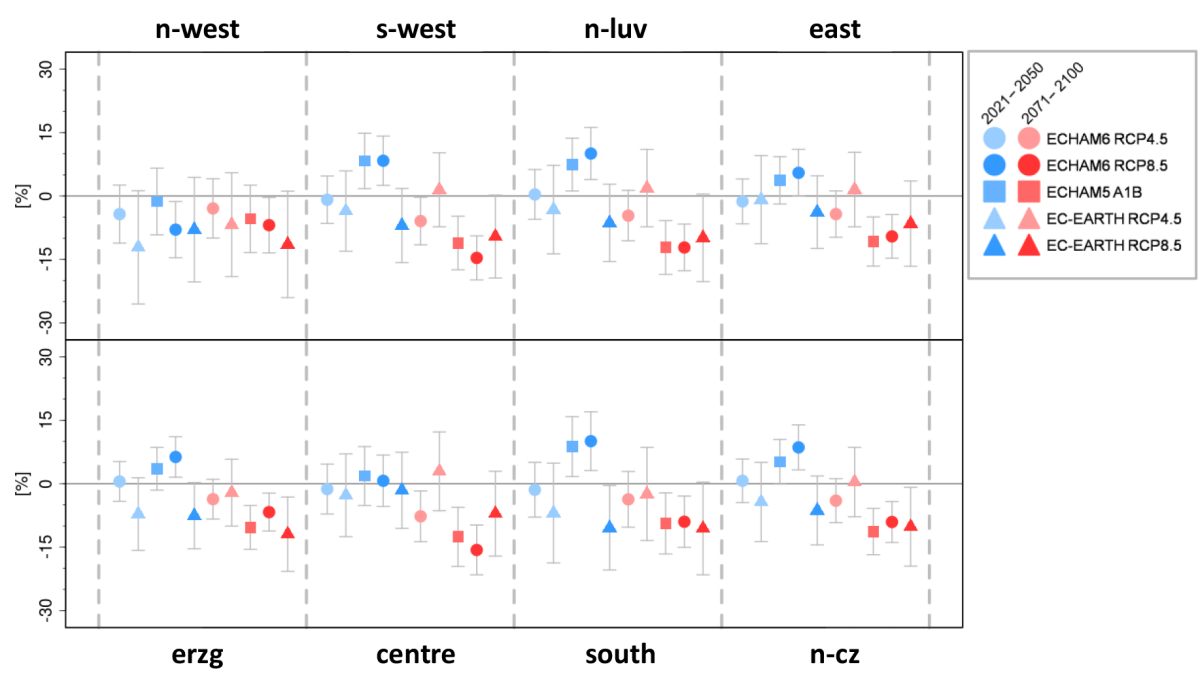

Figure 4. Frequency changes $(\%)$ of extreme precipitation ( $>95 \%$ percentile) in summer for different model predictors: ECHAM6 (RCP4.5/8.5 scenarios), ECHAM5 (A1B scenario) and EC-Earth (RCP4.5/8.5 scenarios). The mean frequency changes for 2021-2050 (blue) and 2071-2100 (red) with respect to the 1971-2000 period are shown with their $95 \%$ confidence intervals (indicating significance if zero is not included).

(Riediger and Gratzki, 2014). The first factor might dominate until the mid-21st century leading to more frequent precipitation extremes, whereas the second factor might prevail with further strengthening climate change leading to less frequent extreme areal precipitation in summer towards the end of the 21 st century.

For autumn, there are no significant changes in precipitation extremes, but for winter, some regions are affected by increasing frequencies of extreme areal precipitation. However, these signals of change are not reproduced for predictors from all global climate models (likewise in spring) and therefore do not prove to be sufficiently robust. Only in summer, a higher degree of accordance is achieved (see Fig. 4): the significantly increasing extremes for the 2021-2050 period are mostly confirmed at least with predictors from ECHAM5 (but not from EC-EARTH), the significantly decreasing ex- tremes for the 2071-2100 period are reproduced in 7 regions with ECHAM5 predictors and in 3 regions with EC-EARTH predictors. Thus, especially the decrease in frequency (and amount, not shown) of extreme areal precipitation in summer might become a widespread phenomenon in southern central Europe towards the end of the 21 st century.

\section{Conclusions}

Based on monthly frequencies of large scale circulation types derived by particular clustering techniques, frequency assessments of precipitation extremes on a regional scale have been performed including projections for two periods in the future (2021-2050 and 2071-2100). The most distinct changes are indicated for the summer season and the strong scenario RCP8.5: frequency increases of regional precipitation ex- 
tremes in the earlier period and even more widespread decreases in the later period. The latter result is confirmed by an independent analysis of changes in cyclone track frequencies with even higher percentages of decreasing regional precipitation extremes than indicated in Figs. 3 and 4 (Hofstätter et al., 2015). This points to an enhanced anticyclonic regime in the future during the summer season. Note, however, that this projected decrease is only valid for extreme areal precipitation as studied in this investigation, not including smallerscale convective rainfall which might gain increased intensity at the same time due to rising humidity in context of global warming.

A possible future change in seasonal characteristics should be considered in forthcoming investigations by more flexible seasonal sections, e.g. overlapping 2-month periods. Further remaining uncertainties in the statistical assessments should be reduced in the future by additionally considering within-type changes in internal characteristics of circulation types which are likewise important for climate variability and change (e.g. Beck et al., 2007). Finally, non-stationarities in the predictor-predictand relationships should also be considered in an explicit manner (e.g. Hertig and Jacobeit, 2013) to improve projections of future climate change on a regional scale.

Data availability. All deliverables can be accessed via https://www.zamg.ac.at/cms/de/klima/forschung/klima/ zeitliche-klimaanalyse/wetrax.

Competing interests. The authors declare that they have no conflict of interest.
Acknowledgements. The WETRAX project has been funded by Bundesministerium für Land- und Forstwirtschaft, Umwelt und Wasserwirtschaft (Austria), Bundesanstalt für Gewässerkunde (Germany) and Bayerisches Staatsministerium für Umwelt und Verbraucherschutz/Bayerisches Landesamt für Umwelt (Germany).

Edited by: R. Benestad

Reviewed by: two anonymous referees

\section{References}

Beck, C., Jacobeit, J., and Jones, P. D.: Frequency and within-type variations of large scale circulation types and their effects on lowfrequency climate variability in Central Europe since 1780, Int. J. Climatol., 27, 473-491, 2007.

Hertig, E. and Jacobeit, J.: A novel approach to statistical downscaling considering non-stationarities: application to daily precipitation in the Mediterranean area, J. Geophys. Res.-Atmos., 118, 520-533, 2013.

Hofstätter, M., Jacobeit, J., Homann, M., Lexer, A., Chimani, B., Philipp, A., Beck, C., and Ganekind, M.: WETRAX - Weather Patterns, Cyclone Tracks and related Precipitation Extremes, Geographica Augustana, 19, 239 pp., 2015.

Philipp, A., Della-Marta, P. M., Jacobeit, J., Fereday, D. R., Jones, P. D., Moberg, A., and Wanner, H.: Long term variability of daily North Atlantic-European pressure patterns since 1850 classified by simulated annealing clustering, J. Climate, 20, 4065-4095, 2007.

Philipp, A., Beck, C., Huth, R., and Jacobeit, J.: Development and comparison of circulation type classifications using the COST 733 dataset and software, Int. J. Climatol., 36, 2673-2691, 2016.

Riediger, U. and Gratzki, A.: Future weather types and their influence on mean and extreme climate indices for precipitation and temperature in Central Europe, Meteorol. Z., 23, 231-252, 2014. 